\title{
Optimalisasi Bit Error Rate Jaringan Optik Hybrid Pada Sistem DWDM Berbasis Soliton
}

\section{Bit Error Rate Optimization of Hybrid Optic Network in DWDM System Based on Soliton}

\author{
Rama Panji Prakoso ${ }^{1, *}$, Eka Wahyudi ${ }^{2}$, Kholidiyah Masykuroh ${ }^{3}$ \\ ${ }^{1,3}$ Program Studi S1 Teknik Telekomunikasi, ${ }^{2}$ Program Studi D3 Teknik Telekomunikasi \\ Fakultas Teknik Telekomunikasi dan Elektro, Institut Teknologi Telkom Purwokerto. \\ Jl. D.I. Panjaitan No. 128 Purwokerto, Indonesia \\ 1,*Penulis korespondensi: 17101115@ittelkom-pwt.ac.id, \\ 22ekawahyudi@ittelkom-pwt.ac.id, ${ }^{3}$ kholidiyah@ittelkom-pwt.ac.id
}

Received on 02-08-2021, accepted on 27-08-2021, published on 19-09-2021

\begin{abstract}
Abstrak
Bit Error Rate (BER) merupakan perbandingan antara kesalahan (error) dengan bit yang dikirimkan keseluruhan. Bit Error Rate berfungsi untuk menguji seberapa banyak kesalahan pembacaan di sisi penerima setiap detiknya. Berdasarkan pengertian dari BER peneliti akan melakukan penelitian performansi Bit Error Rate terhadap pengaruh perubahan daya input laser mulai dari -4, -2, 0, 2, 4 dan perubahan panjang serat optik $20 \mathrm{~km}, 60 \mathrm{~km}$, dan $100 \mathrm{~km}$. Peneliti akan membentuk dua sistem simulasi DWDM dengan menggabungkan dua penguat optik yaitu Raman Optical Amplifier (ROA) dan Erbium Doped Fiber (EDFA) posisi dari penguat optik diletakkan secara Booster-Preamplifier dan Inline-Preamplifier. Berdasarkan perbedaan pada daya input laser BER mengalami peningkatan kelayakan sistem saat daya laser dinaikkan mulai dari $-4 \mathrm{dBm}$ sampai $4 \mathrm{dBm}$. Unjuk kerja yang dihasilkan paling baik adalah 8.97E-23 pada Skenario Inline-Preamplifier. Berdasarkan perbedaan panjang serat optik, semakin jauh panjang serat optik maka kelayakan sistem menurun dengan BER terburuk adalah 0.001 pada panjang serat optik $100 \mathrm{~km}$.
\end{abstract}

Kata kunci: Bit Error Rate, Booster, Inline, Daya input, Preamplifier

\section{Abstract}

Bit Error Rate (BER) is a comparison between the error (error) with the bit sent as a whole. Bit Error Rate is used to test how many errors are read on the receiving end every second. Based on the understanding of BER, researchers will conduct research on the performance of Bit Error Rate on the effect of changes in laser input power ranging from -4, -2, 0, 2, 4 and changes in optical fiber length of $20 \mathrm{~km}, 60 \mathrm{~km}$, and $100 \mathrm{~km}$. Researchers will form two DWDM simulation systems by combining two optical amplifiers, namely Raman Optical Amplifier (ROA) and Erbium Doped Fiber (EDFA). Based on the difference in the input laser power, the BER experienced an increase in the feasibility of the system when the laser power was increased from $-4 \mathrm{dBm}$ to $4 \mathrm{dBm}$. The best performance is 8.97E-23 in the Inline-Preamplifier Scenario. Based on the difference in optical fiber length, the farther the length of the optical fiber, the lower the feasibility of the system with the worst BER is 0.001 at 100 km optical fiber length.

Keywords: Bit Error Rate, Booster, Inline, Input power, PreamplifierPendahuluan

\section{Pendahuluan}

Sistem komunikasi optik adalah salah satu sistem transmisi yang cocok untuk komunikasi dengan bit rate tinggi. Selain kecepatannya yang bisa diandalkan, transmisi optik tahan terhadap gangguan seperti kebisingan dan dispersi [1]. Kabel serat optik terbagi menjadi 3 bagian yang tersusun dari inti (core), 
cladding, dan coating. Inti (core) atau inti serat, adalah bagian paling utama dari serat optik, karena pada bagian ini informasi yang berupa pulsa cahaya ditransmisikan. Sementara pembungkus (cladding) merupakan pelapis core, dan mempunyai bahan dasar yang sama dengan core, tetapi mempunyai indeks bias yang lebih kecil daripada core. Lapisan terluar yaitu coating berfungsi sebagai pelindung core dan cladding dari tekanan fisik [2].

Salah satu teknologi yang dapat digunakan dalam mengirimkan informasi menggunakan media transmisi serat optik adalah Dense Wavelength Division Multiplexing (DWDM) [3]. Dense Wavelength Divion Multiplexing (DWDM) adalah bentuk teknologi multiplexing dalam sistem transmisi jaringan optik yang umumnya digunakan untuk transmisi dengan jarak yang jauh antara satu titik terminasi (terminal) dengan titik terminasi lainnya [4]. Pengaruh jarak komunikasi yang berkaitan dengan redaman dan dispersi merupakan batasan dalam perencanaan, sehingga dibutuhkan penguat optikal yang mendukung teknologi multiplexing [2]. Hybrid optical amplifier diusulkan sebagai solusi meningkatnya beban jaringan. Amplifer hibrida dapat mengurangi akibat induksi non-liniearitas dan mencegah penggunaan biaya tinggi [5].

Jurnal Penelitian Arumidina Islamiq (2017) dengan judul "Analisa Perubahan Posisi Penguat Optik SOA-EDFA" telah membahas bagaimana performansi penguat optik hybrid dalam sistem DWDM hasilnya pemasangan penguat optik hybrid secara serial bisa meningkatkan performansi BER hingga jarak 50 km. Jurnal Penelitian Dodi Zulherman (2018) dengan judul "Comparative Analysis EDFA and ROA in Non linear CWDM System" membahas perbandingan penguat EDFA dan ROA dalam sistem non linear CWDM sistem hasilnya raman optical lebih stabil dalam sistem tersebut.

Berdasarkan latar belakang dan jurnal penelitian terdahulu maka tim penulis akan melakukan analisa unjuk kerja penguat optik hybrid ROA-EDFA pada sistem DWDM berbasis soliton. Bit Error Rate (BER) digunakan sebagai acuan untuk mengetahui kualitas sistem penguat Hybrid pada DWDM berbasis soliton baik atau tidak berdasarkan standar yang telah ditentukan. Parameter variasi yang digunakan adalah perubahan daya input laser mulai dari $-4 \mathrm{dBm}$ sampai $4 \mathrm{dBm}$ dan perubahan panjang serat optik dimulai dari $20 \mathrm{~km}$ sampai dengan $100 \mathrm{~km}$.

\section{KaJian PUSTAKa}

\section{A. Optimalisasi Bit Error Rate}

Mengoptimalkan sistem untuk tingkat kinerja yang diperlukan biasanya dilakukan pada tahap desain sistem transmisi data sehingga parameter kinerja dapat disesuaikan pada awal tahap konsep desain. Proses transmisi data. dari satu titik ke titik lainnya, baik melalui tautan radio / nirkabel atau tautan telekomunikasi kabel, parameter kuncinya adalah berapa banyak kesalahan yang akan muncul dalam data yang muncul di ujung jarak jauh [6]. Pada sistem serat optik, kesalahan bit terutama diakibatkan oleh dispersi optik dan atenuasi yang mungkin ada. Juga noise mungkin masuk ke dalam receiver optik itu sendiri [7].

Bit Error Rate (BER) berfungsi untuk menguji seberapa banyak kesalahan pembacaan di sisi penerima setiap detiknya. Nilai BER dimisalkan dengan pemberlakuan BER sejumlah $10^{-13}$. atau dengan kata lain dalam $10^{-13}$ yang dikirimkan, terdapat 1 bit yang mengalami kesalahan pembacaan atau penerimaan [8]. BER dapat dituliskan dalam bentuk Persamaan 1:

$$
\operatorname{BER}=\frac{1}{2} \operatorname{ercf}\left(\frac{Q}{\sqrt{2}}\right)
$$

Dimana ercf merupakan fungsi error seperti Persamaan 2:

$$
\operatorname{Ercf}(\mathrm{x})=\frac{1}{\sqrt{2}} \int_{x}^{\sim} e \frac{-x^{2}}{2} \mathrm{dx}
$$

Sehingga diperoleh pendekatan seperti Persamaan 3: 


$$
\mathrm{BER}=\mathrm{Pe}(\mathrm{Q})=\frac{1}{\sqrt{2 \pi}} \frac{e \frac{-Q^{2}}{2}}{Q}
$$

\section{Dengan $\mathrm{Q}=\mathrm{Q}$ faktor dan $\mathrm{Pe}=$ Error Probability}

\section{B. Blok Sistem DWDM Berbasis Soliton}

Diagram blok sistem DWDM berbasis soliton dibuat dengan software Optisystem 7.0 terbentuk dari empat blok utama yaitu blok pengirim, media transmisi, penguat optik, dan blok penerima.

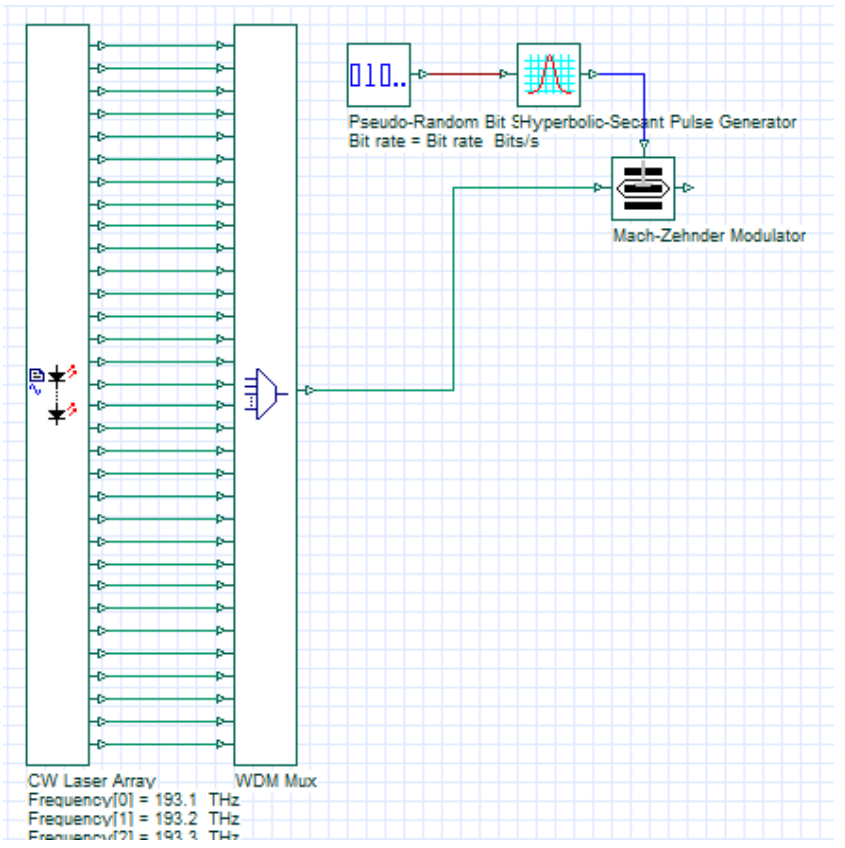

Gambar 1. Blok Pengirim

Gambar 1 merupakan blok pengirim terdiri dari yang terdiri dari CW laser, WDM Demux, Pseudo random binary sequence (PRBS) perangkat ini menggunakan 32 kanal PRBS dengan nilai bitrate setiap kanal $10 \mathrm{Gbps}$, spasi kanal yang digunakan sebesar $100 \mathrm{GHz}$, Secant Hyperbolic perangkat ini menghasilkan bit - bit generator dalam bentuk elektrik dan diubah ke bentuk pulsa soliton. Soliton cocok untuk komunikasi optik karena mampu mempertahankann lebarnya bahkan dengan adanya dispersi serat. Namun, penggunaannya membutuhkan banyak hal perubahan dalam desain sistem dibandingkan dengan sistem non-soliton konvensional [9] , dan Mach-zehnder Modulator merupakan modulator eksternal yang akan memodulasi sinyal informasi sebelum ditransmisikan kedalam serat optik [10].

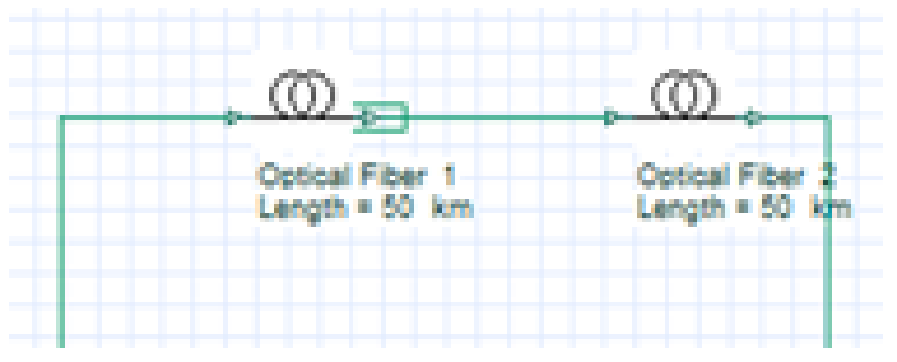

Gambar 2. Media Transmisi

Gambar 2 merupakan blok media transmisi yang tersusun oleh serat optik single mode fiber (SMF) sesuai standar ITU-T G.655. panjang serat optik divariasikan dari 20 km, 60 km, dan $100 \mathrm{~km}$. 


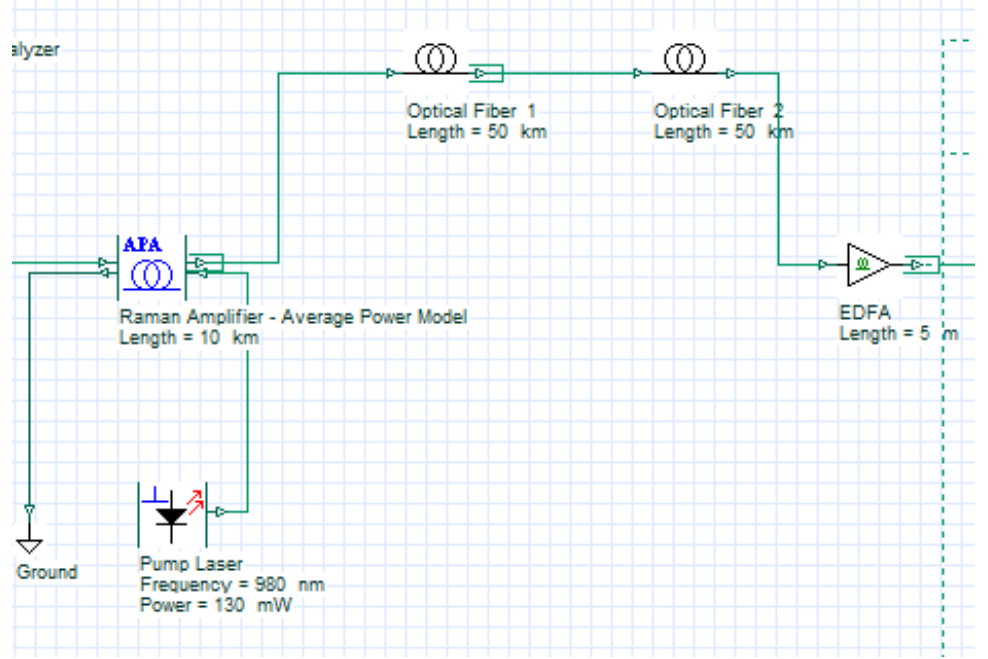

Gambar 3. Penguat Optik

Gambar 3 merupakan blok penguat optik yang terdiri dari Erbium Doped Fiber (EDFA). Penguat ini menghasilkan pertumbuhan kapasitas transmisi yang cepat dengan memanfaatkan keunggulan sistem berbasis WDM [5]. Raman Optical Amplifier (ROA) merupakan penguat harus dipompa secara optik untuk memberikan penguatan ROA membutuhkan daya pemompaan yang jauh lebih tinggi daripada EDFA. Raman tidak membutuhkan dopan khusus untuk melakukan penguatan [9]. Penguat EDFA dan ROA digabungkan menjadi satu rangkaian secara serial atau cascade. Pemasangan secara hybrid menawarkan banyak keuntungan yaitu data rate sistem yang dapat diubah sesuai kebutuhan agar menyesuaikan jumlah saluran yang tersedia [11].

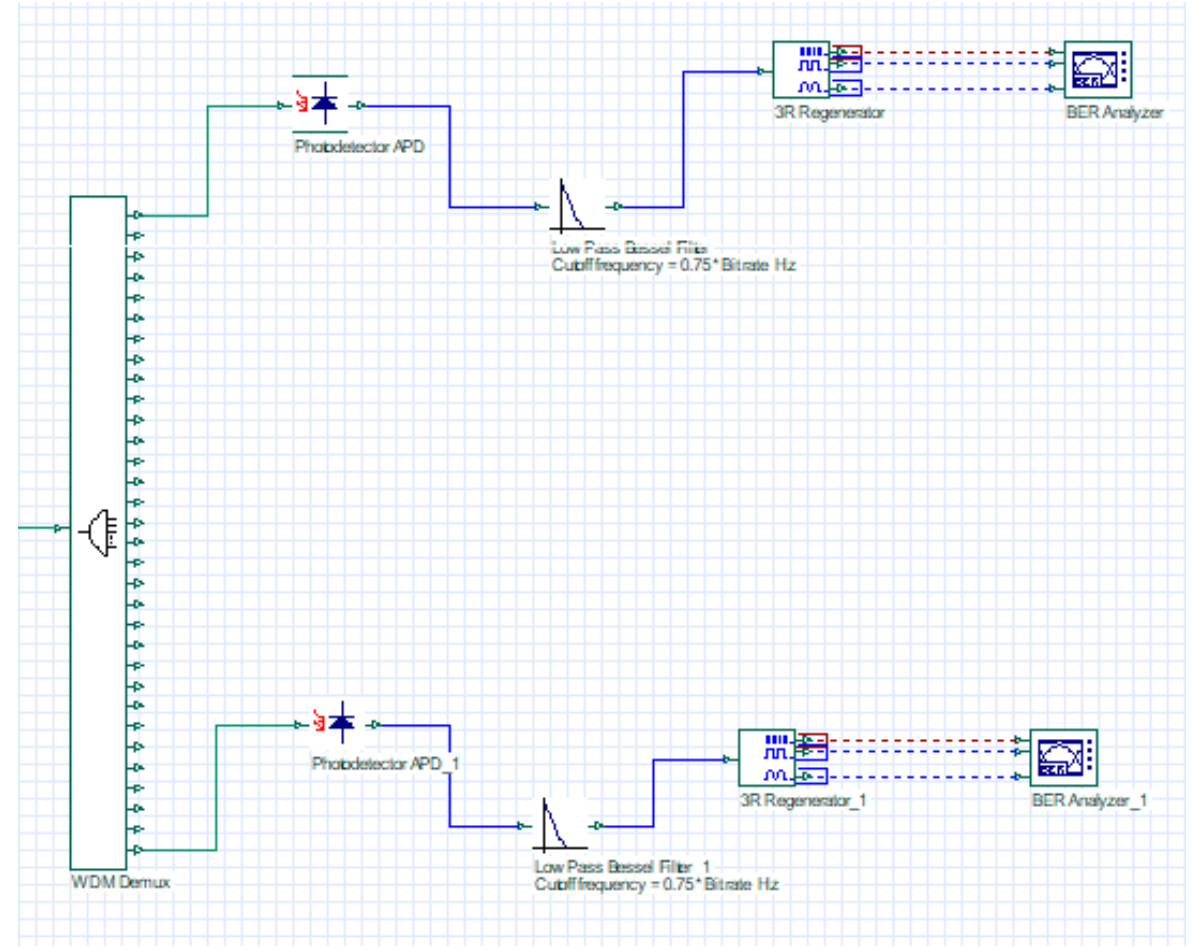

Gambar 4. Blok Penerima

Gambar 4 merupakan blok penerima yang terdiri 4 komponen yaitu WDM Demux, Komponen kedua Sensitivitas photodetector, alat ini bertipe Avalanche Photodiode (APD) yang memiliki sensitivitas lebih 
tinggi ketimbang tipe PIN. Komponen ketiga adalah filter low pass bessel. Filter ini berada disisi penerima yang memiliki kemampuan untuk menyaring noise dari sinyal pada berkas cahaya pada saat proses transmisi. Komponen Keempat adalah 3R Generator dengan menggunakan perangkat tersebut tidak diperlukan koneksi antara transmitter dan BER Analyzer.

\section{Metode Penelitian}

Peneliti melakukan uji unjuk kerja BER terhadap panjang serat optik dan perubahan daya laser. Panjang serat optik yang digunakan mulai dari $20 \mathrm{~km}, 60 \mathrm{~km}, 100 \mathrm{~km}$. Perubahan daya laser dari -4, -2, 0, 2, $4 \mathrm{dBm}$ atau mulai dari daya rendah ke daya tinggi. Peneliti melakukan perubahan penempatan penguat optik, ada 3 macam cara penempatan penguat optik mulai dari booster amplifier (ditempatkan setelah transmitter) cara tersebut dapat meningkatkan level daya sinyal.

Kedua Inline amplifier (ditempatkan di sepanjang link pada titik perantara) yang menggantikan regenerator elektronik. Ketiga Preamplifier (ditempatkan sebelum receiver) dapat meningkatkan daya yang diterima dan meningkatkan sensitivitas [12]. Ketiga penguat divariasikan menjadi 2 skenario yaitu Skenario Booster-Preamplifier dan Skenario Inline-Preamplifer.

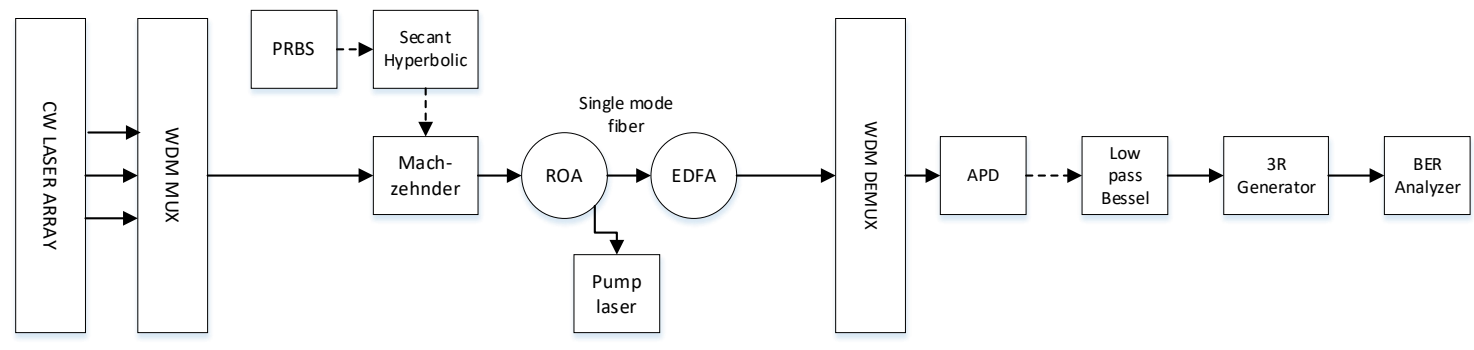

Gambar 5. Skenario Booster-Preamplifer

Gambar 5 merupakan skema dari Skenario Booster-Preamplifier. Penguat ROA diletakkan pada posisi Booster dan penguat EDFA ditempatkan di Preamplifer

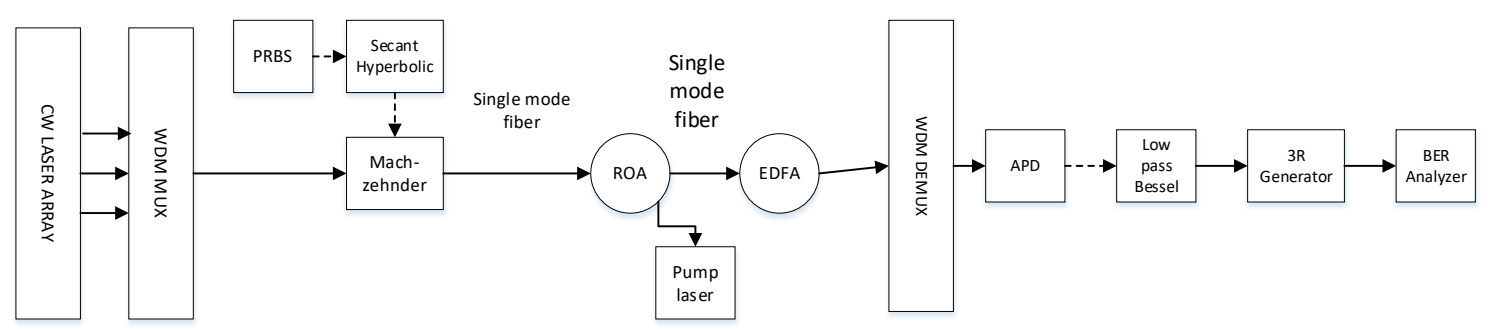

Gambar 6. Skenario Inline-Preamplifer

Gambar 6 menunjukkan penempatan penguat ROA di posisi Inline dan Penguat EDFA berada di posisi Preamplifier. Jadi dari setiap skenario akan dilakukan uji BER berdasarkan perubahan daya input dan perubahan panjang link fiber optik

\section{Hasil dan Pembahasan}

\section{A. Unjuk Kerja BER Terhadap Perubahan Daya}

Uji unjuk kerja BER terhadap perubahan daya dilakukan dengan menggunakan jarak yang sama yaitu $20 \mathrm{~km}$.

Tabel 1. Booster-Preamplifer 


\begin{tabular}{|c|c|}
\hline Daya(dBm) & BER \\
\hline-4 & $1.43 \mathrm{E}-21$ \\
\hline-2 & $1.52 \mathrm{E}-21$ \\
\hline 0 & $2.34 \mathrm{E}-22$ \\
\hline 2 & $1.82 \mathrm{E}-22$ \\
\hline 4 & $2.93 \mathrm{E}-22$ \\
\hline
\end{tabular}

Tabel 1 merupakan hasil simulasi Optisystem dengan posisi penguat optik ROA pada Booster dan EDFA di Preamplifier. Perubahan daya dilakukan mulai dari daya terendah $-4 \mathrm{dBm}$ sampai daya tertinggi $4 \mathrm{dBm}$ pada jarak yang sama yaitu $20 \mathrm{~km}$.

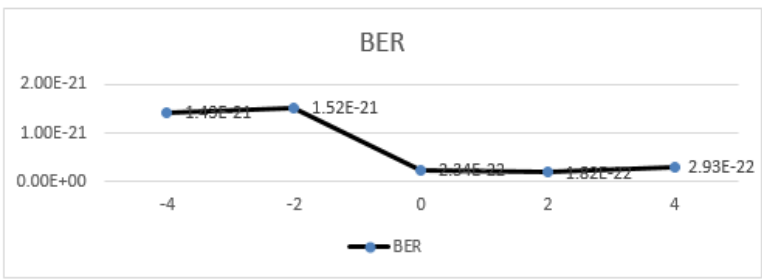

Gambar 7 Skenario Booster-Preamplifier

Gambar 7 menunjukkan grafik dari hasil simulasi pada Skenario Booster-Preamplifier. Peningkatan daya yang dilakukan membuat nilai BER meningkat dari $10^{-21}$ menjadi $10^{-22}$ yang artinya saat daya dinaikkan maka bit error rate menjadi lebih kuat kekuatan antar bit-nya. Sesuai standar ITU-T BER yang bagus memiliki nilai diatas $10^{-9}$, pada jarak $20 \mathrm{~km}$ nilai BER telah memenuhi standar ITU-T dengan daya $4 \mathrm{dBm}$ dengan BER paling baik.

Tabel 2. Inline-Preamplifer

\begin{tabular}{|c|c|}
\hline Daya $(\mathbf{d B m}$ & BER \\
\hline-4 & $6.18 \mathrm{E}-21$ \\
\hline-2 & $2.01 \mathrm{E}-21$ \\
\hline 0 & $2.09 \mathrm{E}-22$ \\
\hline 2 & $8.97 \mathrm{E}-23$ \\
\hline 4 & $1.41 \mathrm{E}-22$ \\
\hline
\end{tabular}

Tabel 2 menunjukkan hasil simulasi dengan penempatan posisi penguat optik yang berbeda. ROA berada di Inline dan EDFA berposisi di Preamplifier. Perubahan daya dilakukan mulai dari daya terendah $-4 \mathrm{dBm}$ sampai daya tertinggi $4 \mathrm{dBm}$ pada jarak yang sama yaitu $20 \mathrm{~km}$.

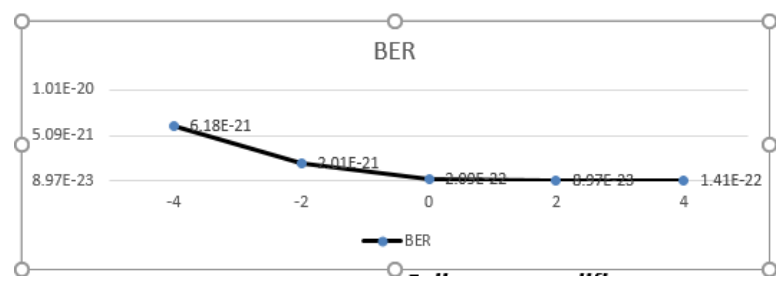

Gambar 8. Skenario Inline-Preamplifier

Gambar 8 menunjukkan grafik unjuk kerja Bit Error Rate (BER) pada posisi Inline-preamplifier hasilnya unjuk kerja BER semakin baik karena nilai BER semakin kecil seiring bertambahnya daya. 
Peneliti membandingkan unjuk kerja Bit Error Rate (BER) terhadap perubahan daya antara dua skenario yaitu perbedaan yang terjadi adalah unjuk kerja BER pada Inline-Preamplifier memiliki nilai BER terbaik 8,97E-23, sementara Booster-Preamplifier unjuk kerja terbaik 2,93E-22. Hasil tersebut menunjukkan bahwa Inline-Preamplifier memiliki unjuk kerja BER yang lebih baik pada perubahan daya karena semakin rendah nilai BER menunjukkan kelayakan sistem yang optimal.

\section{B. Unjuk Kerja BER Terhadap Perubahan Panjang Link Fiber Optik}

Uji unjuk kerja BER ini menggunakan daya yang sama yaitu $4 \mathrm{dBm}$ dengan perubahan panjang serat optik dari $20 \mathrm{~km}, 60 \mathrm{~km}$, dan $100 \mathrm{~km}$.

Tabel 3. Booster-Preamplifier

\begin{tabular}{|c|c|}
\hline Link Optik & BER \\
\hline $20 \mathrm{Km}$ & $2.93 \mathrm{E}-22$ \\
\hline $60 \mathrm{Km}$ & 0.00033 \\
\hline $100 \mathrm{Km}$ & 0.001 \\
\hline
\end{tabular}

Tabel 3 adalah Skenario Booster-Preamplifier, posisi penguat optik ROA pada Booster dan EDFA di Preamplifier.

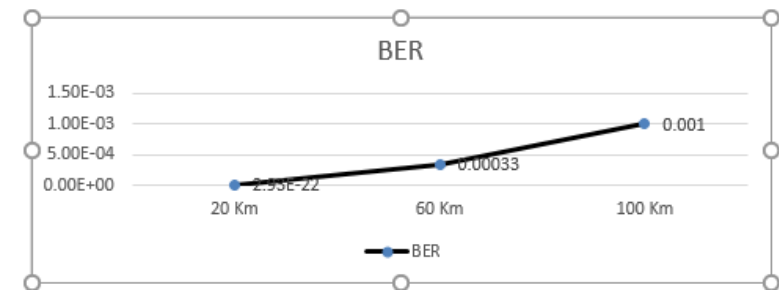

Gambar 9 Skenario Booster-Preamplifier

Gambar 9 merupakan grafik dari perubahan panjang link fiber optik pada Skenario BoosterPreamplifier. Standar nilai BER yang layak menurut ITU-T minimal $10^{-9}$. Pada grafik terlihat panjang serat optik yang semakin meningkat menyebabkan nilai BER menjadi dibawah standar ITU-T, pada jarak $10 \mathrm{~km}$ unjuk kerja BER berada diatas standar yaitu 2,93E-22. Mulai dari panjang serat $60 \mathrm{~km}$ sampai 100 $\mathrm{km}$ unjuk kerja BER meningkat menjadi 0,001 atau dibawah $10^{-9}$. Hasil tersebut menunjukkan unjuk kerja Bit Error Rate paling optimal pada jarak dibawah $60 \mathrm{~km}$.

Tabel 4. Inline-Preamplifier

\begin{tabular}{|c|c|}
\hline Link Optik & BER \\
\hline $20 \mathrm{~km}$ & $1.41 \mathrm{E}-22$ \\
\hline $60 \mathrm{~km}$ & $2.68 \mathrm{E}-12$ \\
\hline $100 \mathrm{~km}$ & 0.0011 \\
\hline
\end{tabular}

Tabel 4 adalah hasil simulasi dari Skenario Inline-Preamplifier. Penguat ROA berada di Inline dan penguat EDFA berada di Preamplifier. 


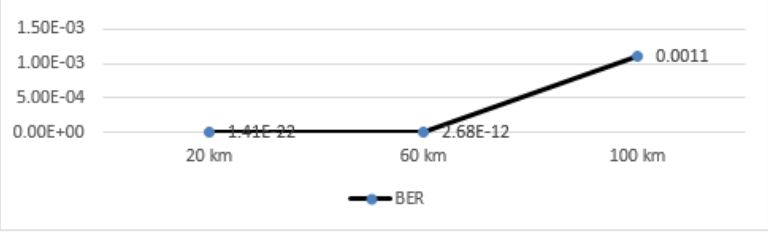

Gambar 10. Skenario Inline-Preamplifier

Gambar 10 menunjukkan grafik unjuk kerja BER pada Skenario Inline-Preamplifier. Panjang serat optik yang bertambah menyebabkan unjuk kerja BER semakin meningkat dibawah standar ITU-T. Peneliti menemukan perbedaaan pada panjang serat optik $60 \mathrm{~km}$ unjuk kerja BER berada diatas standar minimal yaitu 2,68E-12, kemudian kembali berada dibawah standar pada $100 \mathrm{~km}$ dengan nilai 0,0011. Hasil ini menunjukkan Inline-Preamplifier memiliki unjuk kerja BER yang layak dari panjang serat optik $20 \mathrm{~km}$ sampai $60 \mathrm{~km}$. Dibandingkan Booster-Preamplifier hanya sampai panjang serat optik $20 \mathrm{~km}$ saja unjuk kerja BER optimal.

\section{Kesimpulan}

Melalui hasil simulasi yang telah dilakukan penulis mengambil kesimpulan bahwa Unjuk kerja BER pada Inline-Preamplifier memiliki nilai BER terbaik 8,97E-23, sementara Booster-Preamplifier unjuk kerja terbaik 2,93E-22. Hasil tersebut menunjukkan bahwa Inline-Preamplifier memiliki unjuk kerja BER yang lebih baik pada perubahan daya karena semakin rendah nilai BER menunjukkan kelayakan sistem yang optimal. Inline-Preamplifier memiliki unjuk kerja BER yang layak dari panjang serat optik $20 \mathrm{~km}$ sampai $60 \mathrm{~km}$. Dibandingkan Booster-Preamplifier hanya sampai panjang serat optik $20 \mathrm{~km}$ saja unjuk kerja BER optimal.

\section{KONTEN TERKAIT}

Lampiran

Lampiran untuk artikel ini dapat diunduh melalui: http://journal.ittelkompwt.ac.id/public/journals/1/v3n2/2._Lampiran_RP_2.pdf. Lampiran berisi: Gambar BER Analyzer Booster-Preamplifier pada jarak $20 \mathrm{~km}$ dengan daya $-4 \mathrm{dBm},-2 \mathrm{dBm}, 0 \mathrm{dBm}, 2 \mathrm{dBm}, 4 \mathrm{dBm}$; Gambar BER Analyzer Inline-preamplifier pada jarak $20 \mathrm{~km}$ dengan daya $-4 \mathrm{dBm},-2 \mathrm{dBm}, 0 \mathrm{dBm}, 2 \mathrm{dBm}, 4$ $\mathrm{dBm}$; Gambar BER Analyzer pada panjang serat $20 \mathrm{~km}, 60 \mathrm{~km}, 100 \mathrm{~km}$ dengan daya $4 \mathrm{dBm}$

\section{UCAPAN TERIMAKASIH}

Tim penulis mengucapkan terima kasih kepada Bapak Lukman Leksono, S.Pd.,M.Pd selaku dosen wali yang telah memberikan referensi tentang jurnal penelitian yang berkaitan sehingga memudahkan tim penulis dalam mengumpulkan data. Selanjutnya Tim penulis berterima kasih kepada rekan - rekan kelas S1 TT 05 C yang telah membantu dalam memberi kritik dan saran agar karya tulis ini menjadi lebih baik.

\section{Kontribusi Penulis}

RPP Sebagai perancang simulasi dan menjalankan simulasi, KM melakukan review dan analisis hasil simulasi, EW menyusun skenario penelitian dan melakukan pengecekan simulasi agar sesuai skenario.

\section{Daftar Pustaka}

[1] D. Zulherman, S. Utami, and F. Fahmi, "Comparative Analysis of Erbium Doped Fiber Amplifier (EDFA) and Raman Optical Amplifier (ROA) in Nonlinear-CWDM System," J. Infotel, vol. 10, no. 3, p. 144, 2018.

[2] S. Danaryani, Y. Syamsul, and I. Krisnadi, "Studi Perancangan Jaringan Komunikasi Serat Optik Dwdm L Band dengan Penguat Optikal Edfa," Setrum, vol. 4, no. 2, pp. 16-20, 2015. 
[3] A. Sudibyo, F. Khair, and D. Zulherman, "Analisis Unjuk Kerja Penguat Hybrid pada Sistem DWDM ( Dense Wavelength Division Multiplexing ),” pp. 408-412, 2018.

[4] L. M. M. Dwdm, "Perancangan dan Analisis Sistem Komunikasi Serat Optik," Jnteti, vol. 4, no. 3, 2015.

[5] A. Hambali and B. Pamukti, "Performance analysis of hybrid optical amplifier in long-haul ultra-dense wavelength division multiplexing system," ICCREC 2017 - 2017 Int. Conf. Control. Electron. Renew. Energy, Commun. Proc., vol. 2017-January, pp. 80-83, 2017.

[6] A. Islamiq, I. A. Hambali, and A. D. Pambudi, "ANALISIS PERBANDINGAN PERFORMANSI POSISI PENGUAT OPTIK HYBRID SOA - EDFA (Semiconductor Optical Amplifier - Erbium Doped Fiber Amplifier) PADA SISTEM DWDM (Dense Wavelength Division Multiplexing) BERBASIS SOLITON," e-Proceeding Eng., vol. 4, no. 1, pp. 132-139, 2017

[7] I. Poole, "Bit Error Rate, BER is a key parameter for measuring the performance of a data wired or wireless data channel.," www.electronics-notes.com.

[8] Z. N. KARIMAH, A. HAMBALI, and S. SUWANDI, "Analisis Perbandingan Kinerja Mach-Zehnder berdasarkan Ragam Format Modulasi pada Jaringan FTTH," ELKOMIKA J. Tek. Energi Elektr. Tek. Telekomun. Tek. Elektron., vol. 5, no. 1, p. 73, 2018.

[9] G. P. Agrawal, Fiber Optic Communication System, Third Edit. New York: Wiley Interscience, 2002.

[10] S. Singh, A. Singh, and R. S. Kaler, "Performance evaluation of EDFA, RAMAN and SOA optical amplifier for WDM systems," Optik (Stuttg)., vol. 124, no. 2, pp. 95-101, 2013.

[11] J. M. Senior, Optical Fiber Communication Principle and Practice, Third Edit. London: Pearson Education, 2009.

[12] T. Saktioto, S. P. Dewi, R. F. Syahputra, O. Okfalisa, and S. Syamsudhuha, "Raman amplifier performance in pre-amplifier use for optical fiber communication systems," Telkomnika (Telecommunication Comput. Electron. Control., vol. 17, no. 5, pp. 2194-2199, 2019. 